\title{
CENTRO HÍPICO NA CIDADE DE PRESIDENTE PRUDENTE- SP
}

Juliana Elaine dos Santos, Maria Alessandra Bacaro Boscoli

Universidade do Oeste Paulista - UNOESTE, Curso de Arquitetura e Urbanismo, Presidente Prudente, SP. E-mail: allyboscoli@gmail.com

\section{RESUMO}

O cavalo foi um animal importante para história mundial. A criação do automóvel, o equino perdeu espaço sendo usados apenas na área rural. Com a criação dos leilões agropecuários, os cavalos ganharam maior importância, tanto para o trabalho e aprimoramento das raças. O centro hípico contribuiria para o melhoramento genético com reprodução, esportes equestres com lazer/serviço e equoterapia, oferecendo terapia não medicamentosa. $O$ presente trabalho apresenta uma breve história do agronegócio, as referências projetuias, o partido arquitetônico, e o memorial descritivo do projeto. A forma dos blocos foi baseada em uma ferradura e diretrizes Projetuais o projeto da propriedade.

Palavras-chave: instalações equestres, esportes equestres, cavalos, instalações rurais

\section{CENTER EQUESTRIAN IN CITY OF PRESIDENTE PRUDENTE - SP}

\begin{abstract}
The horse was an important animal to world history. The creation of the automobile, the horse lost space being used only in rural areas. With the creation of agricultural auctions, horses became more important, both for work and improvement of breeds. The equestrian center would contribute to the genetic improvement in breeding, equestrian sports with leisure / service and hippotherapy, offering no drug therapy. This paper presents a brief history of agribusiness, the projetuias references, the architectural party, and the specification of the project. The shape of the blocks was based on a horseshoe and guidelines projective property design.
\end{abstract}

Keywords: equestrian facilities, equestrian sports, horses, rural facilities 


\section{INTRODUÇÃO}

$\mathrm{O}$ artigo reúne dados sobre um tipo de empreendimento usado no agronegócio brasileiro, abordando uma proposta de implantação de um centro hípico na cidade de Presidente Prudente. Com a agitação do mundo moderno, o estresse que isso acarreta as pessoas de grandes e médios centros urbanos estão à procura de um local para descanso. Locais de lazer que seja somente por algumas horas ou um fim de semana, ou seja, um local para recarregar as energias sem sair da cidade. A cidade de Presidente Prudente foi escolhida para este trabalho, pelo o fato de ser a maior cidade do oeste do estado de São Paulo, tendo sua origem a partir da Estrada de Ferro Sorocabana, e suas raízes econômicas na pecuária e no plantio de algodão. Para o crescimento destas cidades interioranas desde o Brasil colonial, foram usados cavalos, tanto para trabalho na zona rural, como meio de transporte. Com surgimento do automóvel, os animais foram perdendo espaço, sendo usados apenas nos esportes equestres, e na lida de gado.

A partir dos anos 1990 começou a criação de leilões agropecuários, esses animais ganharam maior importância, tanto para o trabalho e no melhoramento das raças. Com isso ouve uma maior procura de projetos na área da arquitetura rural. O objetivo deste estudo foi Projetar instalações hípicas, resgatar a qualidade de vida e o convívio entre o homem x natureza, e homem x animal. Quebrar paradigmas das tipologias tradicionais, incentivar a pratica de esportes equestres e a terapia não medicamentosa.

\section{METODOLOGIA}

Para a estruturação deste artigo foi baseado em pesquisas in loco, nos agronegócios a serem utilizados, na cidade de Presidente Prudente, identificações de carências projetuais, e ambientação do empreendimento. Pesquisas bibliográficas referentes aos esportes equestres, equoterapia. Pesquisas referenciais para o projeto ser desenvolvido.

\section{BREVE HISTORIA DO COMPLEXO DO AGRONEGOCIO DO CAVALO.}

Segundo o MAPA (2014), o Brasil tem o terceiro maior rebanho de equinos do mundo com 8 milhões de cabeças, adicionados os muares (mulas) e asininos (asnos). O maior na América Latina, que movimenta $\mathrm{R} \$ \mathbf{7 , 3}$ bilhões, apenas com a produção de cavalos. O Complexo do Agronegócio do Cavalo envolve 30 segmentos que são distribuídos entre insumos, criação e destinação final, compondo a base do mesmo. Para o CEPEA (2006), a equideocultura na maioria das vezes apresenta um papel duplo, a economia. Um exemplo dado é de uma escola de equitação pode ser tanto um consumidor do produto final, como um elo anterior ao frigorífico no mercado 
de carne de equinos, por fim elaborando uma cadeia de comercialização do produto. A Partir do mesmo as atividades são dividas pelos os aspectos funcionais do cavalo. Os desafios apresentados para o desenvolvimento do setor no Brasil estão à criação de estrutura compatível para as exigências legais do Ministério da Agricultura, que fiscaliza as normas cumpridas no Programa Nacional de Sanidade de Equinos (PNSE), sobre a defesa sanitária animal.

Segundo Cintra, 2011, o mercado de cavalos pode ser dividido em quatro categorias, de acordo com a capacidade de consumo:

1. Equinos destinados a esporte: inclui centro de treinamentos, hípicas, jóqueis clubes e propriedades particulares.

2. Equinos destinados à criação: o segmento de criação ou haras, que teve um declínio na crise, estando hoje estabilizado e acompanhado o crescimento do mercado.

3. Equinos destinados a lazer: atualmente é o segmento com maior potencial de consumo.

4. Equinos de trabalho: utilizados na lida diária com o gado, representando aproximadamente $85 \%$ do rebanho equino brasileiro. Porém sendo responsável por uma pequena parcela do agronegócio do cavalo.

A importância do complexo do agronegócio do cavalo é grande no Brasil. Além de movimentar bilhões de reais na economia anualmente, também movimenta profissões relacionadas às áreas como: veterinários, zootecnias, adestradores, tratadores, etc.

\section{ANTECENDENTES}

A imagem abaixo, mostra os referenciais utilizadas no projeto sendo, o Haras Polana, Hotel Fasano Boa Vista e Pégaso Farm.

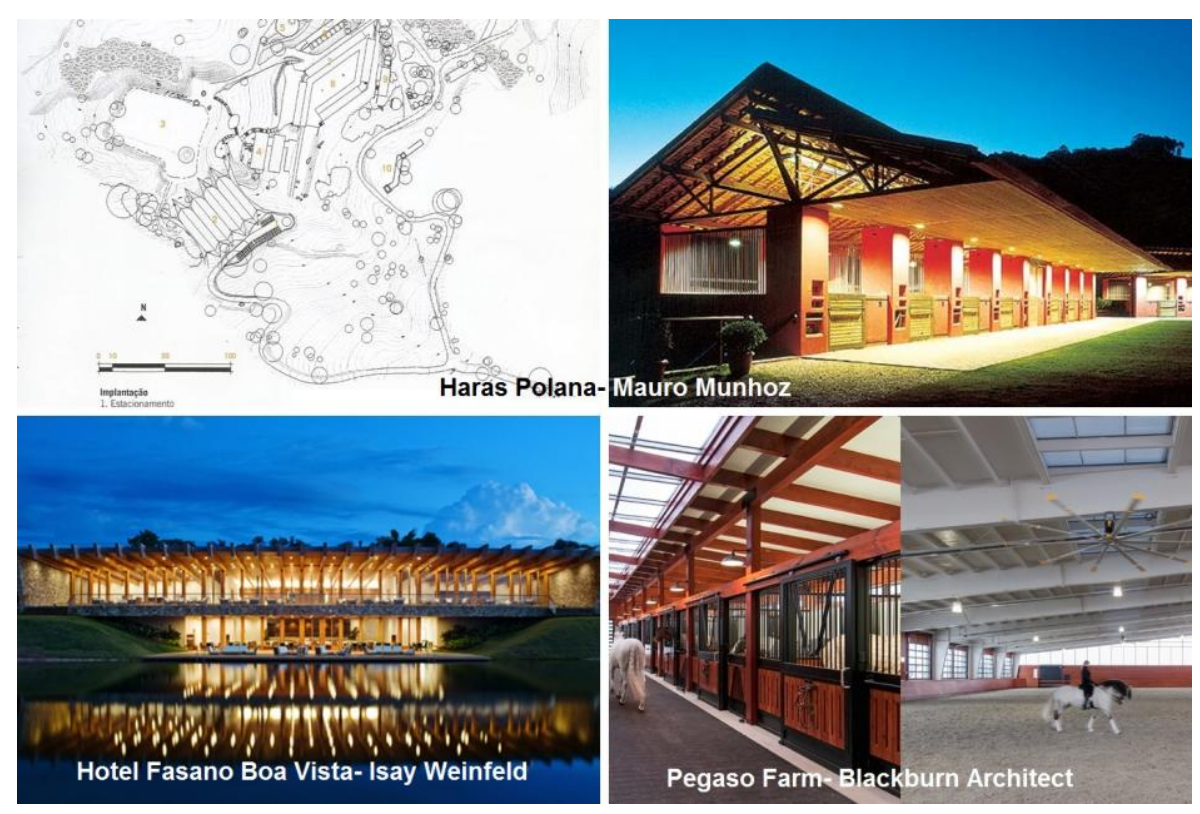

Figura 01. Referenciais 
Fonte: do autor

\section{PROJETO}

Para a ambientação do terreno foi feito o levantamento topográfico, foram levantados os principais acessos da área, que se dá pela Rodovia Assis Chateaubriand, no Km 425, a 3,5 km do aeroporto da cidade, com a extensão de $582.302 .98 \mathrm{~m}^{2}$, ou 5.823 hectare na área rural da cidade. No entorno do terreno encontra-se pontos de referências importantes para o local, como o aeroporto, o rancho quarto de milha e resort Terra Park. A vegetação do terreno mostra-se a área de preservação permanente da borda do rio Santo Anastácio, com algumas árvores no interior do lote. Após feitos os estudos foi confeccionado uma maquete do terreno. A partir da confecção a maquete foi demarcado os caminhos dentro da propriedade em rosa, estacionamentos amarelos, pistas em branco, blocos de apoio em vermelho, cavalariças e centro veterinário em mostarda, e piquetes em preto. (Figura 02).

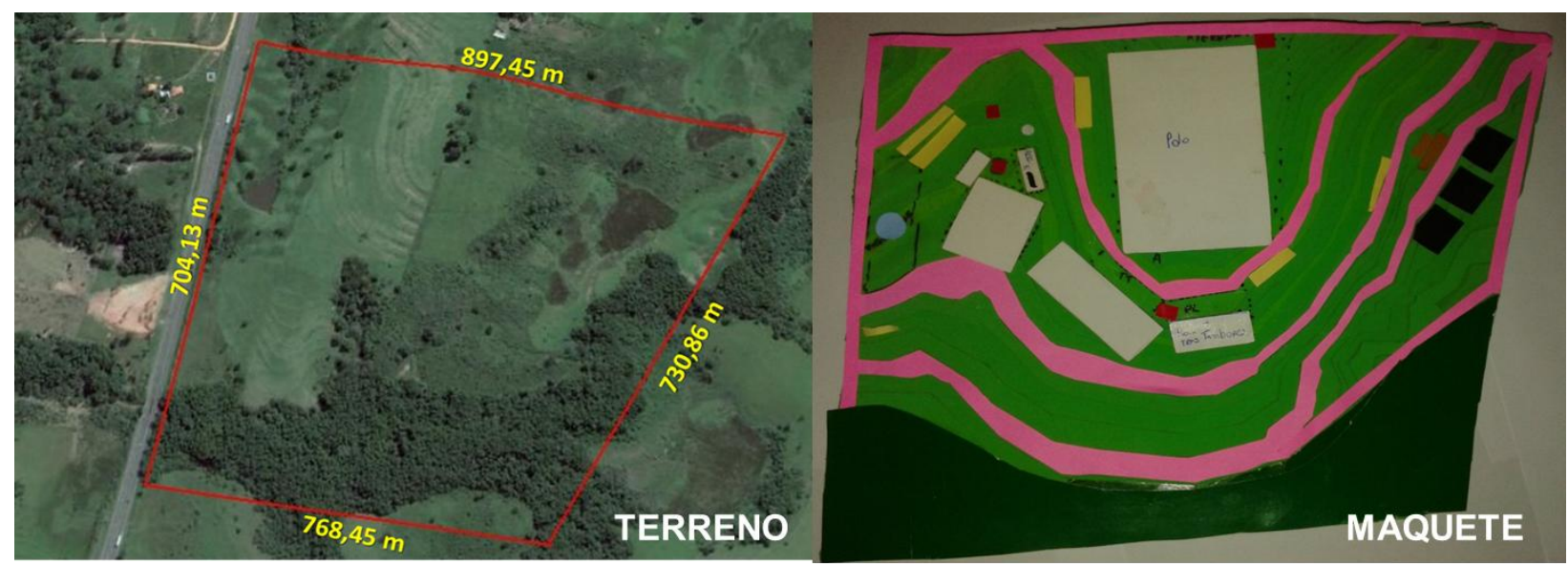

Figura 02. Terreno e Maquete

Fonte: do Autor

6.

PARTIDO ARQUITETONICO

Biselli (2011), cita-se que o partido seria uma consequência formal derivada de uma série de condicionantes como técnicas construtivas, que incluem materiais e intenções plásticas. 0 clima, condições físicas e topográficas, programa de necessidades segundo os usos, condições financeiras, e legislações regulamentadoras e normas sociais. O autor ainda define que partido é uma hipótese de prefiguração do objeto, que o projetista elege como ponto de partida e fio condutor, cabe-se uma investigação de contexto de explicitação das razões que asseguram a tese e validade a essas arquiteturas projetadas. Portanto denomina - se partido arquitetônico a ideia preliminar do edifício projetado.

A ideia preliminar deste projeto é a interação entre o homem, animal e a natureza, com o local onde será implantado, as margens de uma área de preservação permanente que protege o rio 
Santo Anastácio, onde o indivíduo poderá praticar esportes equestres, ou simplesmente cavalgar pela a propriedade. Pessoas com necessidades especiais poderiam praticar equoterapia, e ao mesmo tempo interagir com o espaços, a partir de praças e bosques. A setorização do centro hípico, baseia-se no projeto do Haras Polana do arquiteto Mauro Munhoz. Neste projeto o arquiteto setoriza as instalações no terreno da propriedade, mantendo os blocos de treinamento do lado esquerdo, social ao centro e equestre a direita. Cada instalações do projeto será setorizada pela a frequência de uso do local, com áreas usadas no dia-a-dia instaladas de fronte a rodovia Assis Chateaubriand, com pistas para os esportes e terapia. Ao centro do terreno áreas usadas periodicamente, com pistas de esportes coletivos e regionais. Perto do limite da propriedade as áreas destinadas ao animais, mantendo-os longe dos agito do dia-a-dia, .Os edifícios projetados para o centro hípico, tem forma geometrizada de ferradura, blocos retangulares, interligados por um semicírculo,(Figura 03). No mesmo projeto o arquiteto cria um pátio em forma trapezoidal entres as baias, o mesmo foi tomado como partido. No centro hípico os pátios em forma de um semicírculo interliga as formas retangulares. Somente no centro veterinário e nas cavalariças que os pátios são internos. O mesmo interliga os blocos, e oferece uma vista panorâmica, da área, formado um lobby, como no projeto do Hotel Fasano Boa Vista, do arquiteto Isay Weinfeld. Em alguns edifícios o semicírculo é representado jardins, mantendo a forma inicia, nos demais conforme a referência do Hotel Fasano, a cobertura é composta por vigas de madeiras paralelas, intercalados com vidro estrutural, coberto por uma forração.

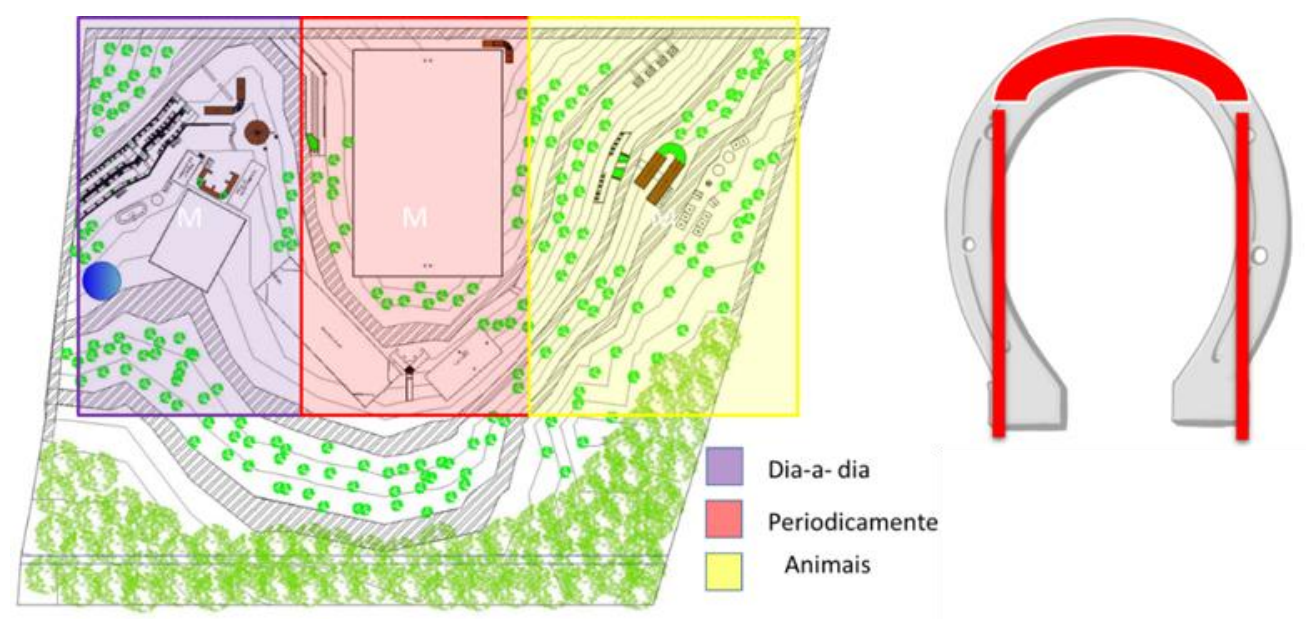

Figura 03. Setoriazação do Centro Hipico, e derivação da forma Fonte: do Autor

\section{MEMORIAL DESCRITIVO}

A entrada da propriedade se dá através da rodovia Assis Chateaubriand, no $\mathrm{Km} \mathrm{425,} \mathrm{O}$ 
caminho principal que percorre toda a propriedade é ladeado por ipês amarelos, (Tabebuia chrysotricha), e os caminhos internos são ladeados por ipês roxos, (Tabebuia impetiginosa). Logo após entrada da propriedade, está localizado o bloco do Hipismo Clássico. O bloco retangular direito abriga a administração do centro hípico, e secretaria. No mesmo está localizado área para funcionários com vestiários e copa/ área de convivência. No centro localizado no semicírculo está o lobby e refeitório que oferece área de alimentação tanto para funcionários como para praticantes. No retângulo esquerdo se localiza a cozinha, área para acompanhantes, vestiários para praticantes e enfermaria. Este prédio oferece apoio as pistas de volteio, adestramento, salto e equoterapia, tendo vista panorâmica para estas pistas. O telhado do bloco é composto por duas águas, com telhas cerâmicas nas formas retangulares, e no semicírculo de pérgulas vedadas por vidro estrutural, com uma forração acima para controle da temperatura. Neste projeto o vidro é usado para manter a integração homem natureza, mesmo estando dentro de um ambiente fechado. 0 bloco seguinte localizado na área de uso frequente é o de volteio, o mesmo abriga um picadeiro que será utilizado tanto para a modalidade, quanto para exercícios de equoterapia, pelo o fato de ser uma pista coberta. É composto somente por arquibancadas. A forma da arquibancada e da cobertura é circular, afim de seguir a forma do picadeiro. O bloco seguinte é usado apenas usado como arquibancada para as pistas de equoterapia, salto e adestramento, porém são pistas descobertas, tendo somente a pista de adestramento coberta. Dois banheiros compõe o bloco. $\mathrm{O}$ blocos seguintes estão localizados na área que será usada periodicamente que contém os blocos do polo, e Hipismo Rural. O bloco do polo está localizado no maior platô existente na propriedade. A modalidade não é muito popular na região, e por ter uma pista com grandes dimensões, porém a propriedade ficaria com uma grande parte sua extensão ociosa. Para solucionar o problema área de leilão será implantada no mesmo local, assim sendo usado em períodos alternados com os jogos. O prédio de polo segue as forma principal de todos os outros blocos, porém a diferença entre os outros. Neste projeto o semicírculo não será vedado com pano de vidro, o lobby ficará aberto, criando uma varanda. Neste local foi utilizado uma malha estrutural para sustentação da cobertura. O bloco Hipismo Rural é o último bloco utilizado para apoio as pistas, se localiza abaixo da pista de polo, no meio da propriedade. O bloco oferece apoio aos praticantes e espectadores das modalidades de três tambores e prova de laço. O bloco possui um mirante, para os visitantes terem uma vista para toda a propriedade e também a área de preservação permanente (APP), e para as pistas do bloco. O centro veterinário e cavalariça, estão instalados no lado direito da propriedade, área destinada aos animais, as baias da cavalariça tem dimensões de $4 \mathrm{~m} \times 4 \mathrm{~m}$, com altura de 2 metros, e com gradil de aço coten até o teto, na frente e nas laterais, com portas de 
correr. As janelas das baias são vedadas por venezianas móveis de madeira, podendo estar aberta nos dias de clima quente, e fechadas no dias de temperatura baixa. A cobertura usada no centro veterinário é de 2 duas águas, já a das cavalariças são de lanternim com aberturas diagonais, com o madeiramento aparente. O interior das baias são pintados com tinta lavável, de cor terrosa, e o piso somente no contra piso revestido por estrado de borracha vedovati para baias coberto por feno. Os pisos externos da cavalariças são piso cimentício, já os piso da área de banho e Ferradoria são revestido por estrado de borracha vedovati para lavadores, a figura abaixo mostra o piso. Após a cavalariça se localiza a áreas destinadas a piquetes e redondel, e girador. Locais para treinamento do animais, ou para um simples pastagem dos animais. A imagem abaixo mostra os blocos do centro hípico.

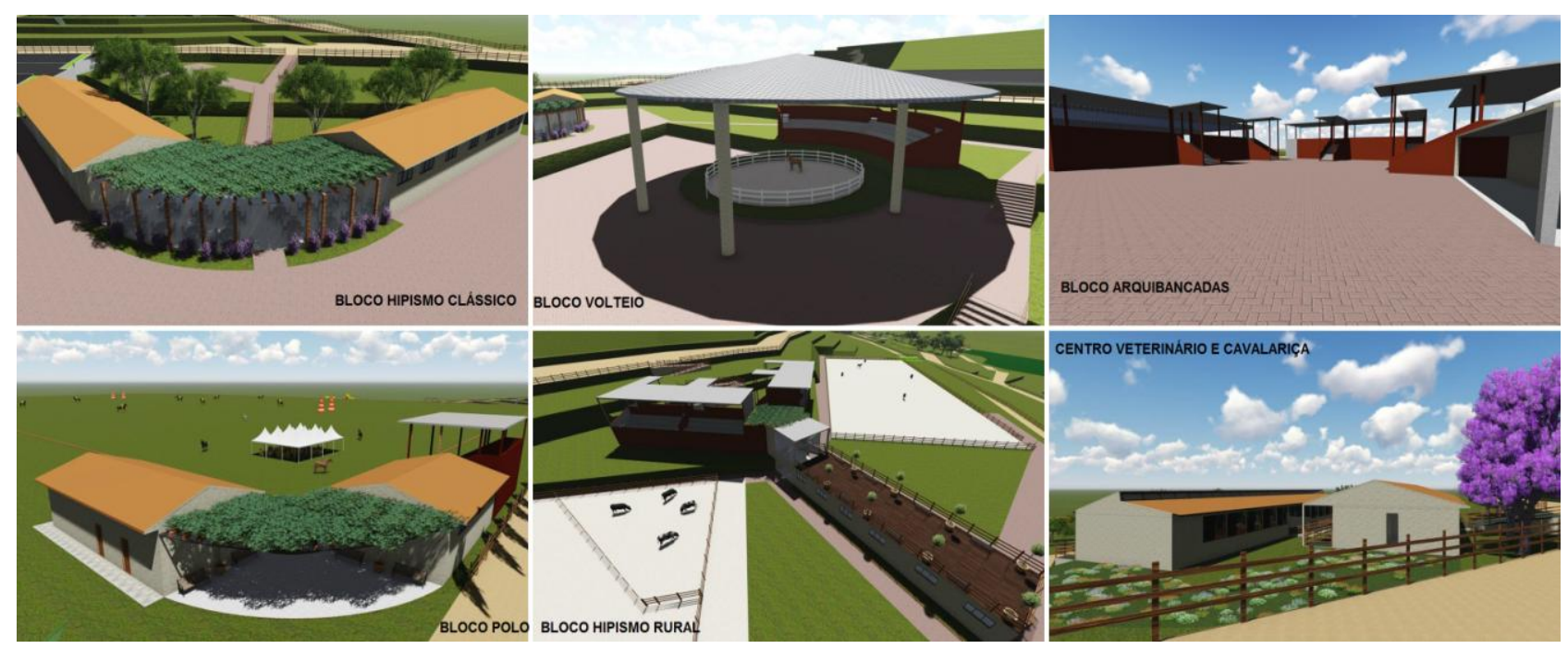

Figura 04. blocos do centro hípico

Fonte: do Autor

\section{RFERÊNCIAS}

ANTUNES, B. Hospede da Fazenda. Revista AU, Arquitetura e Urbanismo, São Paulo, ed. 219, p. 3037, jun. 2012.

BISELLI, M. Teoria e prática do partido arquitetônico. Disponível em: http://www.vitruvius.com.br/revistas/read/arquitextos/12.134/3974, Acesso em 22 fev. 2015 BLACKBURN ARCHITECT. Disponível em <http://blackburnarch.com/projects/pegaso-farm/>. Acesso em 22 set.2014.

Campbell, Judith, Cavalos, 2ª edição, São Paulo: Prisma, 1979.

CEPEA. Centro de Estudos Avançados em economia Aplicada - ESALQ/USP. Estudo do agronegócio cavalo. In RELATORIO FINAL. LIMA, R.A.S; SHIROTA, R; BARROS, G.S.C. Piracicaba, junho 2006.

CINTRA. André Galvão de Campos. O Cavalo - Características, Manejo e Alimentação. Roca, 2011. Vital Book file 
MAPA - Ministério da Agricultura, Pecuária e Abastecimento. Equídeos. Disponível em <http://www.agricultura.gov.br/animal/especies/equideos>. Acesso em: 16/09/14.

Pereira, Milton Fischer, Construções Rurais, 4o edição, São Paulo: Nobel, 1986.

Planejamento, Construção e Reforma de Haras com o arquiteto Marcelo Novaes, Art Video, VHS (34 mim), color, 2000.

SERAPIÃO, F. Técnica e sensibilidade em haras na serra paulista. Projeto Design, São Paulo, ed. 307, p. 44-49, setembro 2005. 